\title{
Clonal Analysis of Mouse Mammary Luminal Epithelial Cell Transplants
}

\author{
Long V. Nguyen,, Maisam Makarem, ${ }^{1}$ Nagarajan Kannan, ${ }^{1}$ Annaick Carles, ${ }^{2}$ \\ Sneha Balani, ${ }^{1}$ Michelle Moksa, ${ }^{2}$ Martin Hirst, ${ }^{2-4}$ and Connie J. Eaves ${ }^{1,5}$
}

$\mathrm{M}$ UCH EFFORT HAS BEEN DEVOTED recently to describing the range of growth and differentiation activities that can be elicited from different phenotypes of normal mammary cells in various conditions [1]. In mice, different genetic lineage-tracing studies have provided evidence of variable self-sustaining properties of cells in the basal and luminal compartments. However, when these cells are prospectively isolated, many mouse basal cells can individually regenerate an entire multibranched mammary gland [1]. In contrast, equivalent regenerative activity has rarely been documented for mouse luminal cells [2], although an ability for it to be activated in vitro has been demonstrated [3]. In this study, we demonstrate the utility of cellular barcoding to define the contributions of individual purified luminal cells to the regeneration of two complete gland structures obtained in two cleared fat pads.

$\mathrm{EpCAM}^{++} \mathrm{CD} 49 \mathrm{f}^{\text {low/- }}$ (luminal) cells were isolated by fluorescent-activated cell sorting (FACS) from normal virgin adult female C57Bl/6J mouse mammary glands (Fig. 1A), transduced at $40 \%$ efficiency with a library of DNA-barcoded green fluorescent protein-encoding lentiviruses, and $1.3 \times 10^{5}$ cells injected with Matrigel into a single cleared fat pad in each of two mice (Fig. 1B) as previously described for mouse basal cell transplants [4]. The purity of the transplanted cells determined by reanalyzing an aliquot of the sorted cells showed $>98 \%$ still displayed a luminal phenotype, with a $<0.2 \%$ chance of being contaminating basal (EpCAM${ }^{\text {low }} \mathrm{CD} 49 \mathrm{f}^{+}$) cells that could subsequently contribute to clone formation.

After 8 weeks, whole-mount microscopy revealed complete branched $\mathrm{GFP}^{+}$structures had been regenerated in both mice (Fig. 1C). Isolation of the EpCAM ${ }^{\text {low }} \mathrm{CD} 49 \mathrm{f}^{+}$ basal cells, EpCAM ${ }^{++} \mathrm{CD}_{4} \mathrm{f}^{\text {low/- }} \mathrm{Sca}^{-}$luminal progenitor

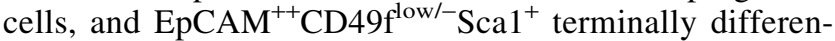
tiated luminal cells from the enzymatically dissociated fat pads (Fig. 1A) revealed that these three subsets were

FIG. 1. (A) FACS plot showing the initial EpCAM ${ }^{++} \mathrm{CD} 49 \mathrm{f}^{\text {low/- }}$ mouse mammary luminal epithelial cells (red circle) that were barcoded and subsequently transplanted. The protocol for enzymatic dissociation and FACS antibodies used are as previously described [4]. The same FACS strategy was used to isolate cells from regenerated glands after 8 weeks in vivo. EpCAM ${ }^{\text {low }} \mathrm{CD} 49 \mathrm{f}^{+}$basal cells (blue), $\mathrm{EpCAM}^{++} \mathrm{CD} 49 \mathrm{f}^{\text {low/- }} \mathrm{Sca}^{-}$luminal progenitor cells (red), and $\mathrm{EpCAM}^{++} \mathrm{CD} 49 \mathrm{f}^{\text {low/- }} \mathrm{Sca}^{+}$terminally differentiated luminal cells (dark yellow). (B) Flow diagram of the experimental design. Isolated EpCAM ${ }^{++} \mathrm{CD} 49 \mathrm{f}^{\text {low/- }}$ mouse mammary luminal epithelial cells were exposed to a large library of barcoded and GFP-encoding lentiviruses for $4 \mathrm{~h}$ followed immediately by their transplantation into the cleared fat pads of prepubertal $\mathrm{C} 57 \mathrm{Bl} / 6 \mathrm{~J}$ mice [4]. After 8 weeks the regenerated glands were retrieved and dissociated into single-cell suspensions and sorted by FACS into the three subsets indicated in (A). (C) Whole-mount microscopy revealed complete branching GFP ${ }^{+}$ structures had been regenerated after 8 weeks in vivo. Scale bar $=1 \mathrm{~mm}$. (D) Table showing the total number of basal, luminal progenitor, and differentiated luminal cells obtained from the regenerated glands. An aliquot of 100 cells was taken from each subset of cells and assayed for CFC activity, as previously described [4]. The CFC frequency in percentage is shown with the mean \pm SD. (E) A heatmap depiction of all 23 clones detected by sequencing the barcodes introduced. The 23 clones are aligned on the horizontal axis, with the vertical axis showing whether they contained basal, luminal progenitor, and/or differentiated luminal cells (blue, red, and yellow, respectively). A gray box means no cells of that type were detected. (F) A ternary plot showing the relative proportions of basal cells, luminal progenitors, and differentiated luminal cells within individual clones, color coded according to whether the clone was bilineage (purple), basal only (blue), or luminal only $(\mathrm{red})$. (G) Distribution of the sizes of bilineage clones (purple), clones of exclusively basal cells (blue), and clones of exclusively luminal cells (red, shown as a percent of the total number of clones of that type). CFC, colony-forming cell; FACS, fluorescent-activated cell sorting; FSC, forward scatter; GFP, green fluorescent protein; SD, standard deviation. Color images are available online.

\footnotetext{
${ }^{1}$ Terry Fox Laboratory, British Columbia Cancer Agency, Vancouver, Canada.

${ }^{2}$ Michael Smith Laboratories, University of British Columbia, Vancouver, Canada.

${ }^{3}$ Department of Microbiology and Immunology, University of British Columbia, Vancouver, Canada.

${ }^{4}$ Canada's Michael Smith Genome Sciences Centre, British Columbia Cancer Agency, Vancouver, Canada.

${ }^{5}$ Department of Medical Genetics, University of British Columbia, Vancouver, Canada.
} 
A

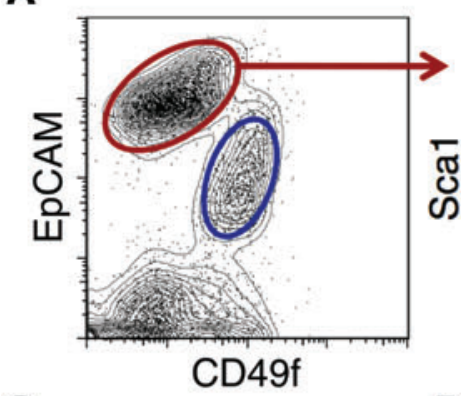

C

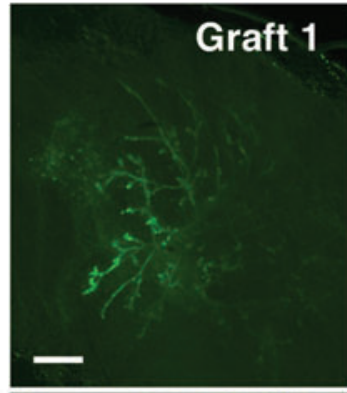

Graft 2

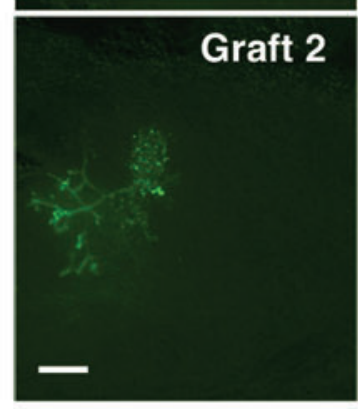

D

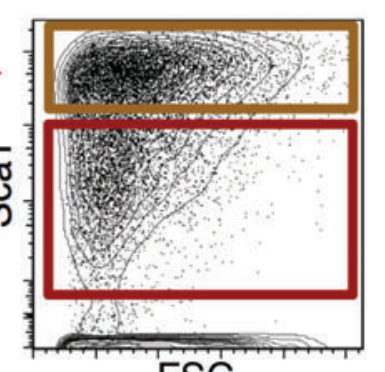

B

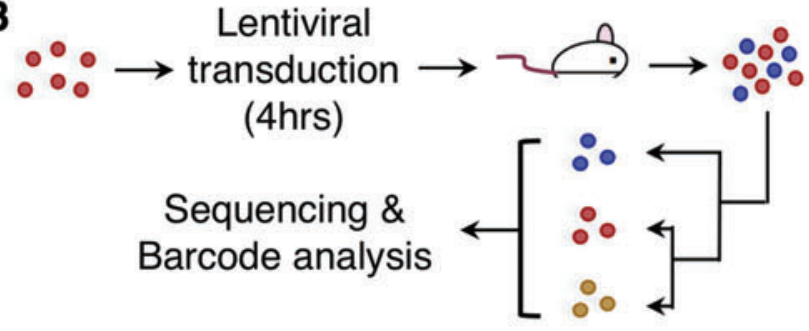

D

\begin{tabular}{|c|c|c|c|c|c|c|}
\hline & \multicolumn{2}{|c|}{$\begin{array}{c}\text { Basal } \\
\left(\text { EpCAM }^{\text {low } C D 49 f^{+}}\right)\end{array}$} & \multicolumn{2}{|c|}{$\begin{array}{c}\text { Luminal } \\
\text { progenitor } \\
\left(\mathrm{EpCAM}^{++} \mathrm{CD} 49 \text { flow }\right. \\
\left.\text { Sca1 }^{-}\right)\end{array}$} & \multicolumn{2}{|c|}{$\begin{array}{c}\text { Differentiated } \\
\text { luminal } \\
\left(\mathrm{EpCAM}^{++} \mathrm{CD} 49 \text { flow }\right. \\
\left.\mathrm{Sca1}^{+}\right)\end{array}$} \\
\hline & Cells & $\begin{array}{c}\text { CFC } \\
(\%)\end{array}$ & Cells & $\begin{array}{c}\text { CFC } \\
(\%)\end{array}$ & Cells & $\begin{array}{c}\text { CFC } \\
(\%)\end{array}$ \\
\hline$\frac{ \pm}{\frac{\pi}{6}}=$ & $\begin{array}{c}9.0 \times 10^{3} \\
(29 \%)\end{array}$ & 46 & $\begin{array}{c}1.3 \times 10^{4} \\
(41 \%)\end{array}$ & 30 & $\begin{array}{c}9.1 \times 10^{3} \\
(30 \%)\end{array}$ & 9 \\
\hline 滎 ॠ & $\begin{array}{c}8.1 \times 10^{2} \\
(26 \%)\end{array}$ & 26 & $\begin{array}{c}1.5 \times 10^{3} \\
(46 \%)\end{array}$ & 20 & $\begin{array}{c}8.8 \times 10^{2} \\
(28 \%)\end{array}$ & 18 \\
\hline$\stackrel{+1}{\text { 돓 }}$ & & $36 \pm 14$ & & $25 \pm 7$ & & $14 \pm 6$ \\
\hline
\end{tabular}

E

Clone \# $\begin{array}{lllllllllllllllllllllll}1 & 2 & 3 & 4 & 5 & 6 & 7 & 8 & 9 & 10 & 11 & 12 & 13 & 14 & 15 & 16 & 17 & 18 & 19 & 20 & 21 & 22 & 23\end{array}$

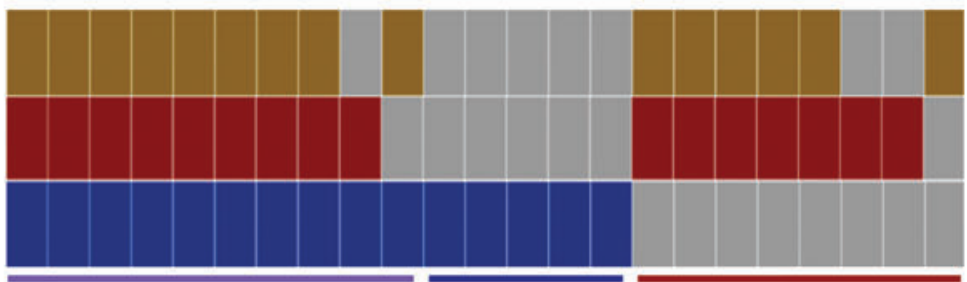

Bi-lineage clones

$\mathbf{F}$

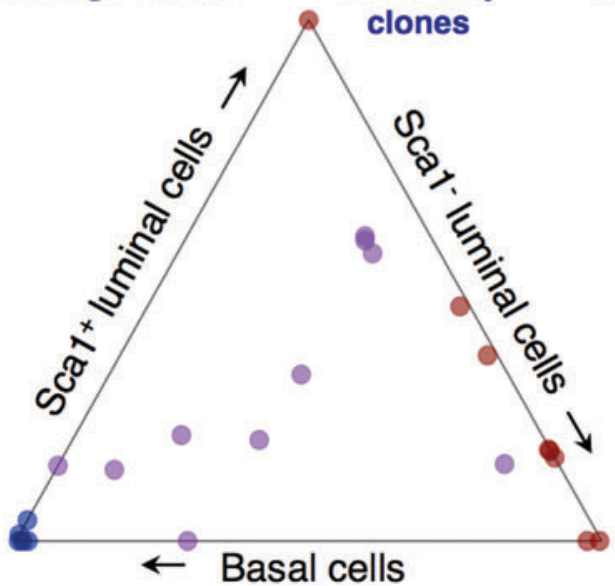

clones

- Bi-lineage clones

- Basal-only clones

- Luminal-only clones
G

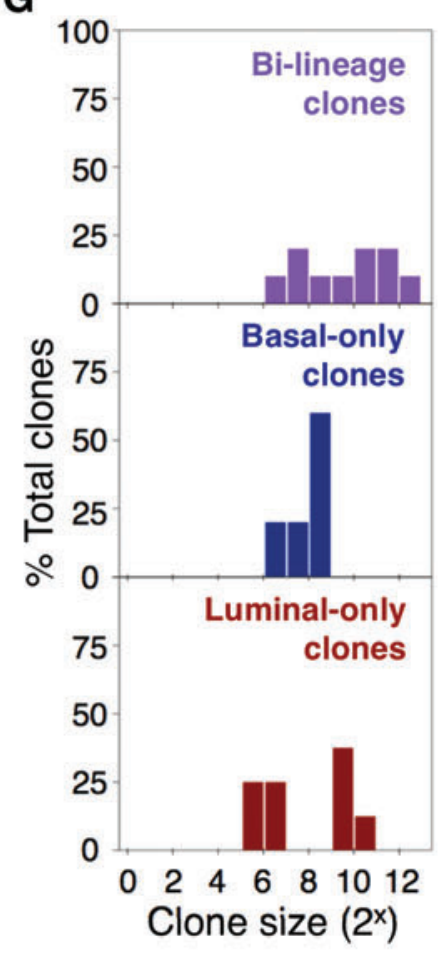


present in similar proportions in both fat pads $(>2$-fold more $\mathrm{Sca}^{-}$and Sca1 ${ }^{+}$luminal cells than basal cells, with the $\mathrm{Sca}^{-}$luminal progenitor fraction more prominent; Fig. 1D), despite a 10-fold difference in the total number of mammary cells recovered from each fat pad $\left(3.1 \times 10^{4}\right.$ vs. $\left.3.2 \times 10^{3}\right)$. A normal adult mammary gland would have a higher proportion of differentiated luminal cells compared with luminal progenitor cells [2], suggesting these regenerated glands may be less mature.

The colony-forming cell (CFC) content in each harvested subset was also largely restricted to the basal and luminal progenitor fractions (frequencies of $\sim 36 \%$ and $\sim 25 \%$, respectively), compared with the $\mathrm{EpCAM}^{++} \mathrm{CD} 49 \mathrm{f}^{\text {low/- }} \mathrm{Sca} 1^{+}$ cells ( 14\%; Fig. 1D). Thus, despite large differences in the overall size of the glands generated from the transplanted cells, their progeny distributions were similar to one another, and also to those found in the normal adult mouse mammary gland [3].

DNA sequencing and barcode analysis [4] detected 14 and 9 clones in the 2 regenerated structures (Fig. 1E). FACS isolation of the different phenotypes in each structure before DNA extraction from them showed that 10 clones ( 7 and 3 clones in the 2 regenerated structures) were bilineage and had a mean size of $\sim 2 \times 10^{3}$ cells each. Five clones contained only basal cells and eight only luminal cells (Fig. 1F) with smaller mean sizes of $\sim 300$ and $\sim 500$ cells per clone, respectively; Fig. 1G).

These findings illustrate the power of cellular barcoding to analyze the clonal outputs of cells with limited growth potential-here applied to rare $\left(\sim 10^{-4}\right)$ transplantable cells isolated from the luminal compartment of the normal adult mouse mammary gland.

\section{Acknowledgments}

The authors thank G. Edin, M. Hale, and D. Wilkinson for excellent technical support; D. Ko and W. Xu (Flow Cytometry Facility, Terry Fox Laboratory) for assistance with flow cytometry; and T. MacDonald for assistance with rodent husbandry. This work was supported by grants from the
Canadian Cancer Society (grant no. 702851) to C.J.E., a CIHR Vanier Canada Graduate Scholarship to L.V.N., a Canadian Institute of Health Research Banting and Best Graduate Fellowship to M.M., and a University of British Columbia Graduate Fellowship to S.B.

\section{Author Disclosure Statement}

The authors have no competing interests to disclose.

\section{References}

1. Visvader JE and J Stingl. (2014). Mammary stem cells and the differentiation hierarchy: current status and perspectives. Genes Dev 28:1143-1158.

2. Shehata M, A Teschendorff, G Sharp, N Novcic, IA Russell, S Avril, M Prater, P Eirew, C Caldas, CJ Watson and J Stingl. (2012). Phenotypic and functional characterisation of the luminal cell hierarchy of the mammary gland. Breast Cancer Res 14:R134.

3. Makarem M, BT Spike, C Dravis, N Kannan, GM Wahl and CJ Eaves. (2013). Stem cells and the developing mammary gland. J Mammary Gland Biol Neoplasia 18:209-219.

4. Nguyen LV, M Makarem, A Carles, M Moksa, N Kannan, P Pandoh, P Eirew, T Osako, M Kardel, et al. (2014). Clonal analysis via barcoding reveals diverse growth and differentiation of transplanted mouse and human mammary stem cells. Cell Stem Cell 14:253-263.

\section{Address correspondence to: \\ Dr. Connie J. Eaves \\ Terry Fox Laboratory British Columbia Cancer Agency Vancouver, BC V5Z $1 L 3$ Canada \\ E-mail: ceaves@bccrc.ca}

Received for publication July 30, 2018 Accepted after revision December 20, 2018 Prepublished on Liebert Instant Online December 20, 2018 